\title{
BMJ Open Forgone care among middle aged and elderly with chronic diseases in China: evidence from the China Health and Retirement Longitudinal Study Baseline Survey
}

Xiangjun Li, ${ }^{1}$ Mingsheng Chen, ${ }^{2,3}$ Zhonghua Wang, ${ }^{2,3}$ Lei $\mathrm{Si}^{4}$

To cite: Li X, Chen M, Wang Z, et al. Forgone care among middle aged and elderly with chronic diseases in China: evidence from the China Health and Retirement Longitudinal Study Baseline Survey. BMJ Open 2018;8:e019901. doi:10.1136/ bmjopen-2017-019901

- Prepublication history for this paper is available online To view these files, please visit the journal online (http://dx.doi org/10.1136/bmjopen-2017019901).

Received 5 October 2017 Revised 31 January 2018 Accepted 5 February 2018

\section{Check for updates}

${ }^{1}$ School of Health Economics and Management, Nanjing University of Chinese Medicine, Nanjing, China

${ }^{2}$ School of Health Policy \& Management, Nanjing Medical University, Nanjing, China ${ }^{3}$ Nanjing Medical University, Institute of Healthy Jiangsu Construction \& Development, Nanjing, China

${ }^{4}$ Centre for the Health Economy, Macquarie University, New South Wales, Australia

Correspondence to Dr Zhonghua Wang; wzh04@njmu.edu.cn

\section{ABSTRACT}

Objective In general, published studies analyse healthcare utilisation, rather than foregone care, among different population groups. The assessment of forgone care as an aspect of healthcare system performance is important because it indicates the gap between perceived need and actual utilisation of healthcare services. This study focused on a specific vulnerable group, middle-aged and elderly people with chronic diseases, and evaluated the prevalence of foregone care and associated factors among this population in China.

Methods Data were obtained from a nationally representative household survey of middle-aged and elderly individuals ( $\geq 45$ years), the China Health and Retirement Longitudinal Study, which was conducted by the National School of Development of Peking University in 2013. Descriptive statistics were used to analyse sample characteristics and the prevalence of foregone care. Andersen's healthcare utilisation and binary logistic models were used to evaluate the determinants of foregone care among middle-aged and elderly individuals with chronic diseases.

Results The prevalence of foregone outpatient and inpatient care among middle-aged and elderly people was $10.21 \%$ and $6.84 \%$, respectively, whereas the prevalence of foregone care for physical examinations was relatively high (57.88\%). Predisposing factors, including age, marital status, employment, education and family size, significantly affected foregone care in this population. Regarding enabling factors, individuals in the highest income group reported less foregone inpatient care or physical examinations compared with those in the lowest income group. Social healthcare insurance could significantly reduce foregone care in outpatient and inpatient situations; however, these schemes (except for urban employee medical insurance) did not appear to have a significant impact on foregone care involving physical examinations

Conclusion In China, policy-makers may need to further adjust healthcare policies, such as health insurance schemes, and improve the hierarchical medical system, to promote reduction in foregone care and effective utilisation of health services.
Strengths and limitations of this study

- The China Health and Retirement Longitudinal Study is the first national survey focusing on middle-aged and elderly individuals, and provides detailed information about respondents and their living spouses.

- This was the first analysis of foregone care among Chinese middle-aged and elderly people with chronic diseases.

- This paper evaluated foregone care only among middle-aged and elderly adults who perceived a need for healthcare but did not seek treatment; however, it did not take into account those not perceiving the need for healthcare; therefore, the prevalence of foregone care may have been underestimated to some extent.

- Cross-sectional data cannot be used to draw causal conclusions.

\section{INTRODUCTION}

Due to the rapidly ageing population and increasing longevity, in addition to increasing improvement in medical care, a growing number of people are living for long periods of time with chronic disease. The WHO reported that chronic diseases kill 40 million people per year, which is equivalent to $70 \%$ of all deaths globally. Each year, 15 million people die from a chronic disease, and $>80 \%$ of these 'premature' deaths occur in low-income and middle-income countries. ${ }^{1}$ In recent years, the number of individuals with chronic diseases in China has continued to rise, with many residents facing serious health challenges. There were 260 million people with chronic diseases in China in 2012, and this number has increased by an average of $8.9 \%$ each year. Deaths from chronic diseases account for $86.6 \%$ of total mortality. As a result of the rapidly ageing population, the number of elderly people in China in 2050 is predicted 
to total $>400$ million, accounting for one-third of the total population, and the average number of chronic diseases that individuals $>60$ years have is estimated at 2.2. China has entered a period of high economic burden caused by chronic diseases, which account for approximately $70 \%$ of the total economic disease burden. ${ }^{2}$ According to a report by WHO in 2015, the direct medical costs for chronic diseases in China were $>\mathrm{US} \$ 500$ billion, and by 2030, rapid ageing may increase the financial burden of chronic diseases by $40 \%$.

Access to equitable healthcare, according to need, and regardless of demographic, ability to pay or social background, is an important goal for worldwide healthcare service systems. ${ }^{3}$ China has implemented a series of healthcare reforms during the past two decades, including the expansion of health insurance coverage and the reformation of the health service system, with the ultimate goal of affordable and equitable healthcare for all. The reforms of the healthcare systems have minimal benefits at the beginning and progress with expanded benefits. ${ }^{4}$ However, healthcare in China remains highly unequal across different subpopulations, and both the demand for, and inequality in, healthcare utilisation have increased significantly in this country, due to its rapidly ageing population. Several studies have addressed this issue by examining factors associated with healthcare utilisation among the elderly in China. ${ }^{5-8}$ Foregone care is another aspect of healthcare access; an individual with forgone care needs is defined as one who does not use healthcare, despite perceiving a need for it. Forgone care is an important aspect in the assessment of healthcare system performance, as it represents the gap between the perceived need and actual utilisation of healthcare services from the citizens' perspective.

Ageing is accompanied by an increase in the prevalence of non-communicable chronic diseases. ${ }^{9}$ In China, the elderly people are more sensitive to the economic burden of diseases overall because of the high prevalence of chronic diseases and low incomes of this population, and the absence of social security mechanisms. ${ }^{10}$ Thus, elderly individuals with chronic diseases may have a higher prevalence of foregone care compared with those who do not have such conditions. Several studies have empirically tested the associations between individual and community factors and foregone care. These studies indicate an association between higher rates of foregone care and female sex, younger age, rural living, lack of health insurance, lack of financial support, low levels of education and poor health. ${ }^{11-16}$ Although foregone care is an area of high interest for researchers and policy-makers, there is a dearth of research on this subject among middle-aged and elderly individuals with chronic disease in China. The overall goal of this study was to identify the prevalence of foregone care and its associated factors among middle-aged and elderly people with chronic conditions. Two specific objectives were defined: (1) comparison of the prevalence of foregone care between middle-aged and elderly individuals with and without chronic diseases and (2) using Anderson's behavioural model, to identify factors associated with foregone care among middle-aged and elderly individuals with chronic diseases.

\section{METHODS AND DATA}

\section{Data source/sample}

This study was based on data from a nationally representative household survey of middle-aged and elderly people, the China Health and Retirement Longitudinal Study (CHARLS; http://charls.ccer.edu.cn/en/page/ data/2013-charlswave1). CHARLS is a biennial survey conducted by the China Centre for Economic Research at Peking University. The sample was drawn in four stages. First, county-level units (counties or urban districts) were sampled directly. These counties cover 28 of 30 provinces in mainland China, other than Tibet. Second, village and community units within county units were chosen with the help of the National Bureau of Statistics, using recently updated village-level population data. The sample used administrative villages (cun) in rural areas and neighbourhoods (shequ) in urban areas as primary sampling units (PSUs). Three PSUs were selected within each county-level unit, using probability proportional to size (PPS) sampling, to select a total of 450 PSUs. Third, household units were selected in each PSU. The sampling frame was constructed using Google Earth base maps, and a computer-assisted personal interview programme was then used to sample households and to conduct the interviews using laptops. Finally, all age-eligible sample households who were willing to participate in the survey were interviewed.

CHARLS baseline data include detailed information about respondents and their living spouses. The main questionnaire includes information on basic demographics, family, health status and functioning, healthcare and insurance, work, retirement and pension, income, expenditure and assets. In the 2013 wave, the survey sample consisted of 18605 individuals $\geq 45$ years old and their spouses. In this paper, we excluded spouses $\leq 45$ years old, and the remaining 18377 observations were included in the analysis.

\section{Statistical analysis}

Binary multivariate logistic regression was applied to estimate ORs of foregone care. The dependent variable 'foregone care' was dichotomised into $0=$ 'reported utilisation of healthcare' and 1 = 'reported non-use of healthcare'. All explanatory variables were recorded as binary variables.

\section{Variable selection}

The dependent variables were three kinds of foregone care: non-use of outpatient services, non-use of inpatient services and non-attendance for physical examination. Participants were asked the following two questions: 'Have you been ill in the last month?' and 'What was the main reason for not seeking outpatient treatment?", and 
the responses were used to estimate 'non-use of outpatient services' (ie, if the participant answered that he/she had been ill and did not seek medical treatment). Participants were asked, 'In the past year, did a doctor suggest that you needed inpatient care but you did not get hospitalised?' and the response was used to estimate 'non-use of inpatient services' (ie, if the participants answered that they did not attend hospital when a doctor had suggested a need for inpatient services). Participants were asked, 'Did you undergo a physical examination in the last 2 years?' and the response used to estimate 'non-use of physical examination' (ie, if the participants answered that they did not undergo a physical examination in the last 2 years).

Independent variables were selected based on Andersen's healthcare utilisation model (a behavioural model). This model has guided systematic investigations into the factors that can lead to the use of healthcare services, including predisposing, enabling and need factors. ${ }^{17}$ Predisposing factors include demographic characteristics and both social structure and health belief-related factors. In our analyses, we included sex, age and marital status as demographic characteristics and education, employment status and family size as social structure factors. Enabling factors are those that make health service resources available to an individual; they can be measured by determination of family attributes, such as income, access to health insurance or other sources of third-party payment. Enabling factors in the community in which the family lives can also affect the use of services. Community attributes include the number of healthcare facilities and personnel in a community and the region of the country, in addition to the rural-urban nature of the community. In our analyses, access to public insurance, income levels and financial transfers received and given were considered as family components, while area of residence and medical facilities were considered indicators of community attributes. Need factors were both perceived need and need diagnosed or evaluated by a healthcare professional; the former was based on self-reported health status, and the latter included chronic diseases, depression, body mass index (BMI) and limitations on activities of daily living (ADL). Variables included in the multivariate model are presented in table 1 .

\section{RESULTS}

\section{Sample characteristics}

The total sample consisted of 18377 respondents $\geq 45$ years old. Missing data were automatically removed during data processing. No chronic disease was reported by $28.88 \%$ of respondents, with $71.12 \%$ reporting $\geq 1$ chronic disease. In CHARLS, the chronic conditions included hypertension, dyslipidaemia, diabetes, cancer, chronic lung, stomach, memory-related, and/or liver diseases, heart problems, stroke, kidney, emotional and nervous problems, arthritis or rheumatism and/or asthma. Patients with chronic diseases were divided into two categories, including individuals with one chronic and those with multiple $(\geq 2)$ chronic diseases in one person.

Descriptive statistics of the characteristics of the individuals with, versus without, chronic conditions are presented in table 2. Chronic disease prevalence was slightly higher among middle-aged and elderly women than men. Middle-aged and elderly individuals aged 45-55 years accounted for $43.28 \%$ of those without chronic disease, which was higher than the proportion of those with one $(36.05 \%)$ or multiple $(26.78 \%)$ chronic diseases; however, with increasing age, the proportion of individuals with one or multiple chronic diseases exceeded that of people without these conditions, indicating that the risk of chronic disease increases with age. The proportion of people without chronic diseases, and with one or multiple chronic diseases gradually increased among middle-aged and elderly people who were divorced/ single/separated or unemployed/retired, indicating that the risk of chronic disease was relatively high among this group. Middle-aged and elderly people with lower educational levels (<lower secondary) and small family size $(\leq 2)$ also had a higher risk of chronic diseases.

Regarding enabling factors, the ratios of population subgroups (total, no chronic diseases, one chronic disease and multimorbidity) with social health insurance did not differ significantly. The ¥1496-8126 income group had the highest probability of having more than two types of chronic disease, and the proportion of people without chronic disease was greater in the high-income, compared with the low-income, group. Compared with middleaged and elderly people who did not receive support from others, people with economic support exhibited an increasing trend $(67.05 \%)$ towards lack of chronic disease, $73.75 \%$ towards one chronic disease and $78.14 \%$ towards multiple chronic diseases; people who provided economic support to others exhibited the opposite trend.

Among need factors, middle-aged and elderly individuals whose self-reported health was fair or poor had an increasing trend towards having no chronic disease (low probability), one or multiple chronic diseases, and those whose self-reported health was good or excellent exhibited the opposite trend. These results indicate that the risk of chronic disease was negatively associated with health status. Depression and probable depression were also associated with a significant increasing trend towards having one or more chronic diseases. There was also an increasing trend in probability from people without chronic disease, to one chronic, and then to multiple chronic diseases among middle-aged and elderly people with BMI $>24$ or with any ADL.

\section{Prevalence of foregone care}

The data presented in table 3 demonstrate the prevalence of foregone care among middle-aged and elderly individuals. Overall, the prevalence of non-use but oughtto-have-used outpatient services within the last 4 weeks was $10.21 \%$, and the prevalence of non-use of inpatient services was $6.84 \%$. Comparisons of foregone care among 
Table 1 Dependent and independent variables

\begin{tabular}{|c|c|c|}
\hline & Categories & Indicators/survey questions \\
\hline \multicolumn{3}{|l|}{ Dependent variables } \\
\hline $\begin{array}{l}\text { Non-use of outpatient } \\
\text { services }\end{array}$ & $\begin{array}{l}\text { Reported non-use of outpatient/no reported non- } \\
\text { use of outpatient services }\end{array}$ & $\begin{array}{l}\text { Questions: Have you been ill in the last month? What was the } \\
\text { main reason for not seeking outpatient treatment? }\end{array}$ \\
\hline $\begin{array}{l}\text { Non-use of inpatient } \\
\text { services }\end{array}$ & $\begin{array}{l}\text { Reported non-use of inpatient/no reported non- } \\
\text { use of inpatient services }\end{array}$ & $\begin{array}{l}\text { Question: In the past year, did a doctor suggest that you } \\
\text { needed inpatient care but you were not get hospitalised? }\end{array}$ \\
\hline $\begin{array}{l}\text { Non-use of physical } \\
\text { examinations }\end{array}$ & $\begin{array}{l}\text { Not undergoing physical examination/ } \\
\text { undergoing physical examination }\end{array}$ & $\begin{array}{l}\text { Question: Did you have a physical examination in the last } \\
2 \text { years? }\end{array}$ \\
\hline \multicolumn{3}{|l|}{ Predisposing factors } \\
\hline Sex & Male/female & \\
\hline Age (years) & $\leq 55 / 56-65 / 66-75 / \geq 75$ & \\
\hline Marital status & Not married/married & Question: What is your marital status? \\
\hline Household numbers & $\leq 2$ persons in household/ $\geq 3$ persons in household & Number of household members \\
\hline \multicolumn{3}{|l|}{ Enabling factors } \\
\hline Social health insurance & $\begin{array}{l}0, \text { no social health insurance/1, UEMI/2, URMI/3, } \\
\text { NCMI }\end{array}$ & $\begin{array}{l}\text { Question: Are you the policy holder/primary beneficiary of any } \\
\text { type of health insurance? }\end{array}$ \\
\hline Income level & 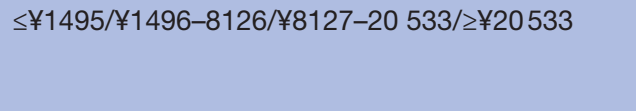 & $\begin{array}{l}\text { Yearly household income divided by the number of household } \\
\text { members; first household member with a weight of } 1 \text {, all } \\
\text { following household members with a weight of } 0.5 \text {. }\end{array}$ \\
\hline Transfer received & $\begin{array}{l}\text { Financial transfers received from others/ } \\
\text { no financial transfers received from others }\end{array}$ & $\begin{array}{l}\text { The total amount of financial transfers that the respondent and } \\
\text { spouse received in the past year. }\end{array}$ \\
\hline $\begin{array}{l}\text { Depression (Center for } \\
\text { Epidemiological Survey } \\
\text { (CESD) scores) }\end{array}$ & $\begin{array}{l}\text { No depression }(C E S D<10) / \text { probability of } \\
\text { being depression }(10 \leq C E S D<20) / \text { depression } \\
(C E S D \geq 20)\end{array}$ & Ten questions of the CESD (Depression Scale) \\
\hline BMI & $\leq 18.5 / 18.624 / \geq 24.1$ & $\mathrm{BMI}$ is the weight divided by the square of the height. \\
\hline ADL & Without ADL/with any ADL & $\begin{array}{l}\text { The ADLs proposed by Wallace and Herzog }{ }^{30} \text { in their paper, } \\
\text { including bathing, dressing and eating. Getting in/out of bed } \\
\text { was added in CHARLS. }\end{array}$ \\
\hline Drinking & No/yes & Whether the respondent drank alcoholic beverages in the past \\
\hline Smoking & No/yes & $\begin{array}{l}\text { Whether the respondent reports ever having smoked or } \\
\text { presently smoking }\end{array}$ \\
\hline
\end{tabular}

ADL, activities of daily living; BMI, body mass index; CHARLS, China Health and Retirement Longitudinal Study; NCMI, new cooperative medical insurance; UEMI, urban employee medical insurance; URMI, urban resident medical insurance.

different groups demonstrated that the underutilisation rate was higher among people with multiple chronic diseases. Furthermore, the results demonstrate that individuals without chronic disease had the highest probability of not having undergone a physical examination in the last 2 years.

\section{Multivariate regression analysis}

Binary logistic models were constructed to examine the determinants of foregone care among middle-aged and elderly Chinese people with chronic diseases. Estimated coefficients describing the predicted effects of the variables are presented in table 4 . We also calculated overall significance values for a multivariate logistic regression 
Table 2 Sample characteristics of middle-aged and elderly people

\begin{tabular}{|c|c|c|c|c|c|}
\hline & $\begin{array}{l}\text { Total, } \\
\mathrm{n}=18377\end{array}$ & $\begin{array}{l}\text { No chronic disease, } \\
\mathrm{n}=5308 \\
(28.88 \%)\end{array}$ & $\begin{array}{l}\text { One chronic, } \\
\mathrm{n}=5279 \\
(28.73 \%)\end{array}$ & $\begin{array}{l}\text { Multimorbidity, } n=7790 \\
(42.39 \%)\end{array}$ & $P$ values \\
\hline \multicolumn{6}{|l|}{ Predisposing factors } \\
\hline \multicolumn{6}{|l|}{ Sex } \\
\hline Male & $47.73 \%$ & $50.58 \%$ & $48.74 \%$ & $45.11 \%$ & \multirow[t]{2}{*}{0.00} \\
\hline Female & $52.27 \%$ & $49.42 \%$ & $51.26 \%$ & $54.89 \%$ & \\
\hline \multicolumn{6}{|l|}{ Age (years) } \\
\hline $45-55$ & $33.76 \%$ & $43.28 \%$ & $36.05 \%$ & $26.78 \%$ & \multirow[t]{4}{*}{0.00} \\
\hline $56-65$ & $37.85 \%$ & $35.31 \%$ & $37.43 \%$ & $39.60 \%$ & \\
\hline $66-75$ & $19.75 \%$ & $13.62 \%$ & $18.85 \%$ & $23.88 \%$ & \\
\hline$\geq 75$ & $8.63 \%$ & $7.79 \%$ & $7.66 \%$ & $9.75 \%$ & \\
\hline \multicolumn{6}{|l|}{ Marital status } \\
\hline Divorced/single/separated & $11.51 \%$ & $9.07 \%$ & $10.93 \%$ & $13.56 \%$ & \multirow[t]{2}{*}{0.00} \\
\hline Married/partnered & $88.49 \%$ & $90.93 \%$ & $89.07 \%$ & $86.44 \%$ & \\
\hline \multicolumn{6}{|l|}{ Employment/retirement status } \\
\hline Employed & $65.53 \%$ & $75.76 \%$ & $68.75 \%$ & $56.57 \%$ & \multirow[t]{4}{*}{0.00} \\
\hline Unemployed & $1.72 \%$ & $1.58 \%$ & $1.61 \%$ & $1.89 \%$ & \\
\hline Retired without pension & $11.28 \%$ & $10.18 \%$ & $10.29 \%$ & $12.67 \%$ & \\
\hline Retired with pension & $21.48 \%$ & $12.48 \%$ & $19.34 \%$ & $28.88 \%$ & \\
\hline \multicolumn{6}{|l|}{ Education } \\
\hline Less than primary school & $44.03 \%$ & $39.43 \%$ & $44.34 \%$ & $46.93 \%$ & \multirow[t]{4}{*}{0.00} \\
\hline Less than lower secondary & $43.07 \%$ & $45.36 \%$ & $43.53 \%$ & $41.19 \%$ & \\
\hline $\begin{array}{l}\text { Upper secondary and vocational } \\
\text { training }\end{array}$ & $12.91 \%$ & $15.21 \%$ & $12.13 \%$ & $11.87 \%$ & \\
\hline Tertiary & & & & & \\
\hline \multicolumn{6}{|l|}{ Family size } \\
\hline$\leq 2$ & $34.84 \%$ & $31.99 \%$ & $33.12 \%$ & $37.95 \%$ & \multirow[t]{2}{*}{0.00} \\
\hline$\geq 3$ & $65.16 \%$ & $68.01 \%$ & $66.88 \%$ & $62.05 \%$ & \\
\hline \multicolumn{6}{|l|}{ Enabling factors } \\
\hline \multicolumn{6}{|l|}{ Public insurance } \\
\hline No public insurance & $4.70 \%$ & $6.37 \%$ & $4.44 \%$ & $3.74 \%$ & \multirow[t]{4}{*}{0.00} \\
\hline UEMI & $14.02 \%$ & $13.40 \%$ & $12.57 \%$ & $15.43 \%$ & \\
\hline URMI & $7.28 \%$ & $7.20 \%$ & $6.64 \%$ & $7.76 \%$ & \\
\hline NCMI & $74.00 \%$ & $73.03 \%$ & $76.34 \%$ & $73.07 \%$ & \\
\hline \multicolumn{6}{|l|}{ Income level } \\
\hline$\leq ¥ 1495$ & $24.97 \%$ & $24.10 \%$ & $24.82 \%$ & $25.56 \%$ & \multirow[t]{4}{*}{0.00} \\
\hline$¥ 1496-8126$ & $24.99 \%$ & $22.75 \%$ & $24.82 \%$ & $26.38 \%$ & \\
\hline$¥ 8127-20533$ & $24.99 \%$ & $26.36 \%$ & $24.47 \%$ & $24.54 \%$ & \\
\hline$\geq ¥ 20533$ & $25.06 \%$ & $26.80 \%$ & $25.89 \%$ & $23.52 \%$ & \\
\hline \multicolumn{6}{|l|}{ Transfer received } \\
\hline No & $26.26 \%$ & $32.95 \%$ & $26.22 \%$ & $21.86 \%$ & \multirow[t]{2}{*}{0.00} \\
\hline Yes & $73.74 \%$ & $67.05 \%$ & $73.78 \%$ & $78.14 \%$ & \\
\hline \multicolumn{6}{|l|}{ Transfer given } \\
\hline No & $29.51 \%$ & $27.46 \%$ & $29.11 \%$ & $31.12 \%$ & \multirow[t]{2}{*}{0.00} \\
\hline Yes & $70.49 \%$ & $72.54 \%$ & $70.89 \%$ & $68.88 \%$ & \\
\hline Living area & & & & & \\
\hline
\end{tabular}


Table 2 Continued

\begin{tabular}{|c|c|c|c|c|c|}
\hline & $\begin{array}{l}\text { Total, } \\
\mathrm{n}=18377\end{array}$ & $\begin{array}{l}\text { No chronic disease, } \\
n=5308 \\
(28.88 \%)\end{array}$ & $\begin{array}{l}\text { One chronic, } \\
n=5279 \\
(28.73 \%)\end{array}$ & $\begin{array}{l}\text { Multimorbidity, } n=7790 \\
(42.39 \%)\end{array}$ & $P$ values \\
\hline Urban & $37.75 \%$ & $37.43 \%$ & $35.85 \%$ & $39.16 \%$ & 0.00 \\
\hline Rural & $62.25 \%$ & $62.57 \%$ & $64.15 \%$ & $60.84 \%$ & \\
\hline \multicolumn{6}{|l|}{ Need factors } \\
\hline \multicolumn{6}{|l|}{ Self-reported of health } \\
\hline Excellent & $1.37 \%$ & $2.97 \%$ & $1.27 \%$ & $0.38 \%$ & 0.00 \\
\hline Very good & $10.06 \%$ & $19.23 \%$ & $10.04 \%$ & $3.90 \%$ & \\
\hline Good & $14.26 \%$ & $21.82 \%$ & $15.20 \%$ & $8.54 \%$ & \\
\hline Fair & $52.51 \%$ & $48.99 \%$ & $56.82 \%$ & $51.95 \%$ & \\
\hline Poor & $21.80 \%$ & $6.99 \%$ & $16.67 \%$ & $35.24 \%$ & \\
\hline \multicolumn{6}{|l|}{ Depression (CESD scores) } \\
\hline No depression & $68.52 \%$ & $80.10 \%$ & $72.24 \%$ & $58.27 \%$ & 0.00 \\
\hline Probability of being depressed & $26.66 \%$ & $17.93 \%$ & $24.21 \%$ & $34.16 \%$ & \\
\hline Depression & $4.82 \%$ & $1.98 \%$ & $3.55 \%$ & $7.58 \%$ & \\
\hline \multicolumn{6}{|l|}{ BMI } \\
\hline$\leq 18.5$ & $48.74 \%$ & $53.75 \%$ & $51.78 \%$ & $43.49 \%$ & 0.00 \\
\hline $18.6-24$ & $5.77 \%$ & $6.01 \%$ & $5.87 \%$ & $5.56 \%$ & \\
\hline$\geq 24.1$ & $45.49 \%$ & $40.24 \%$ & $42.35 \%$ & $50.96 \%$ & \\
\hline \multicolumn{6}{|l|}{$A D L$} \\
\hline Without ADL & $88.37 \%$ & $92.67 \%$ & $91.87 \%$ & $83.06 \%$ & 0.00 \\
\hline With any ADL & $11.63 \%$ & $7.33 \%$ & $8.13 \%$ & $16.94 \%$ & \\
\hline \multicolumn{6}{|l|}{ Drinking } \\
\hline Never & $55.04 \%$ & $53.69 \%$ & $55.38 \%$ & $55.72 \%$ & 0.06 \\
\hline Ever & $44.96 \%$ & $46.31 \%$ & $44.62 \%$ & $44.28 \%$ & \\
\hline \multicolumn{6}{|l|}{ Smoking } \\
\hline Never & $57.66 \%$ & $57.03 \%$ & $58.12 \%$ & $57.78 \%$ & 0.50 \\
\hline Ever & $42.34 \%$ & $42.97 \%$ & $41.88 \%$ & $42.22 \%$ & \\
\hline
\end{tabular}

Calculations were weighted using individual sampling weights and adjusted for household and individual responses.

ADL, activities of daily living; BMI, body mass index; CESD,Center for Epidemiological Survey, Depression; NCMI, new cooperative medical insurance; UEMI, urban employee medical insurance; URMI, urban resident medical insurance.

model (Wald $\chi^{2}$ value and $\mathrm{p}$ value; table 4 ), which indicated that the overall significance of the model was strong.

With the exception of sex, all other predisposing factors were predicted to have significant impacts on foregone healthcare. Specifically, middle-aged and elderly people $>55$ years old were less likely to report outpatient or physical examination foregone care compared with those $<55$ years old. Individuals who were married or had a larger family ( $>2$ members) had a higher likelihood of foregone physical examination, while those with high levels of education had a significantly lower likelihood of foregone physical examination. Middle-aged and elderly people with chronic diseases who were retired without pensions exhibited a higher likelihood of outpatient and inpatient foregone care compared with retired people with pensions.

Table 3 Prevalence of foregone care among middle-aged and elderly people

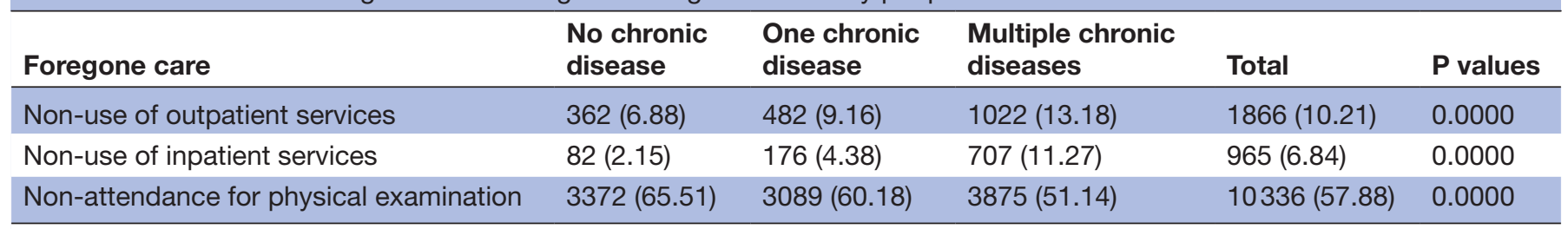

Calculations were weighted using individual sampling weights and adjusted for household and individual responses. 
Table 4 Logistic regression model of forgone care among middle-aged and elderly individuals with chronic diseases

\begin{tabular}{|c|c|c|c|}
\hline $\begin{array}{l}\text { Non-use of outpatient } \\
\text { services }\end{array}$ & & inpatient & $\begin{array}{l}\text { Non-attendance for } \\
\text { physical examination }\end{array}$ \\
\hline SD & OR & SD & OR \\
\hline
\end{tabular}

Predisposing factors

Sex, ref: female

1.06

0.16

0.94

0.21

1.04

0.11

Age (years), ref: $\leq 55$

$\begin{array}{lllllll}56-65 & 0.65^{\star \star \star} & 0.08 & 1.19 & 0.19 & 0.79^{\star \star \star} & 0.07 \\ 66-75 & 0.56^{\star \star \star} & 0.09 & 0.63^{\star \star} & 0.14 & 0.52^{\star \star \star} & 0.06 \\ \geq 75 & 0.59^{\star} & 0.17 & 0.66 & 0.24 & 0.52^{\star \star \star} & 0.09\end{array}$

Marital status, ref: divorced/single/separated 0.95

$0.16 \quad 0.84$

0.16

$1.24^{* *}$

0.13

Employment/retirement status, refer: retired with pension

\begin{tabular}{|c|c|c|c|c|c|c|}
\hline Employed & 1.05 & 0.15 & $0.68^{\star *}$ & 0.12 & 1.13 & 0.11 \\
\hline Unemployed & $1.92^{*}$ & 0.71 & 1.15 & 0.57 & 1.39 & 0.41 \\
\hline Retired without pension & $1.03^{* * *}$ & 0.14 & $1.08^{*}$ & 0.15 & 1.22 & 0.16 \\
\hline \multicolumn{7}{|c|}{ Education, ref: under primary school } \\
\hline Junior school & 1.11 & 0.13 & 0.1 & 0.15 & 0.92 & 0.07 \\
\hline High school and above & 1.01 & 0.20 & $0.61^{*}$ & 0.18 & $0.79^{\star}$ & 0.11 \\
\hline Family size, ref: $\leq 2$ & 0.96 & 0.10 & 0.93 & 0.13 & $1.34^{\star \star \star}$ & 0.09 \\
\hline
\end{tabular}

Enabling factors

Social health insurance, ref: no insurance

\begin{tabular}{|c|c|c|c|c|c|c|}
\hline UEMI & $0.73^{\star \star \star}$ & 0.12 & $0.51^{\star *}$ & 0.15 & $0.41^{\star \star *}$ & 0.09 \\
\hline URMI & $0.81^{*}$ & 0.18 & $0.93^{\star \star}$ & 0.13 & 0.93 & 0.20 \\
\hline NCMI & $0.68^{\star \star}$ & 0.15 & $0.58^{\star \star}$ & 0.15 & 0.76 & 0.14 \\
\hline \multicolumn{7}{|l|}{ Income level, ref: $\leq ¥ 1495$} \\
\hline$¥ 1496-8126$ & 1.22 & 0.16 & 1.09 & 0.19 & 0.93 & 0.08 \\
\hline$¥ 8127-20533$ & 1.03 & 0.15 & 0.88 & 0.17 & $0.85^{*}$ & 0.08 \\
\hline$\geq ¥ 20533$ & 0.80 & 0.14 & $0.63^{\star \star}$ & 0.15 & $0.62^{\star \star \star}$ & 0.07 \\
\hline Financial transfer received, ref: not received & $1.01^{*}$ & 0.13 & 1.35 & 0.26 & 1.10 & 0.10 \\
\hline Financial transfer given, ref: not given & 1.07 & 0.13 & 1.19 & 0.19 & $0.85^{\star \star}$ & 0.07 \\
\hline Area of residence, refer: urban & $1.17^{\star \star \star}$ & 0.07 & 0.85 & 0.12 & $1.44^{\star \star \star}$ & 0.12 \\
\hline
\end{tabular}

Need factors

Self-reported health, ref: poor

\begin{tabular}{|c|c|c|c|c|c|c|}
\hline Fair & $0.85^{\star}$ & 0.09 & $0.51^{\star \star \star}$ & 0.07 & $1.19^{\star \star}$ & 0.09 \\
\hline Good & $0.71^{\star *}$ & 0.13 & $0.33^{* * *}$ & 0.09 & 1.21 & 0.14 \\
\hline Very good & $0.52^{*}$ & 0.17 & $0.27^{\star \star \star}$ & 0.12 & 0.82 & 0.13 \\
\hline Excellent & 0.33 & 0.35 & 0.83 & 0.85 & 1.86 & 0.94 \\
\hline Multiple chronic, ref: one chronic & $1.32^{\star \star \star}$ & 0.14 & $2.74^{\star \star \star}$ & 0.46 & $0.73^{\star \star \star}$ & 0.05 \\
\hline \multicolumn{7}{|l|}{ Depression, ref: no depression } \\
\hline Probability of being depressed & $1.54^{\star \star \star}$ & 0.17 & $1.42^{\star \star}$ & 0.21 & $1.21^{\star \star}$ & 0.09 \\
\hline Depression & $1.49^{\star \star}$ & 0.29 & $2.32^{\star \star \star}$ & 0.55 & 1.18 & 0.17 \\
\hline \multicolumn{7}{|l|}{ BMI, ref: 18.6-24 } \\
\hline$\leq 18.5$ & 0.84 & 0.15 & 0.7 & 0.16 & $1.39^{* *}$ & 0.20 \\
\hline$\geq 24.1$ & $0.60^{\star \star \star}$ & 0.11 & $0.57^{\star \star}$ & 0.13 & 1.17 & 0.17 \\
\hline$A D L$, ref: without $A D L$ & $1.33^{\star *}$ & 0.20 & 1.26 & 0.22 & 0.86 & 0.09 \\
\hline Drinking, ref: never drank & 0.97 & 0.11 & 0.92 & 0.14 & 0.89 & 0.07 \\
\hline Smoking, ref: never smoked & 0.95 & 0.14 & 0.95 & 0.20 & $1.23^{* *}$ & 0.12 \\
\hline
\end{tabular}

Continued 


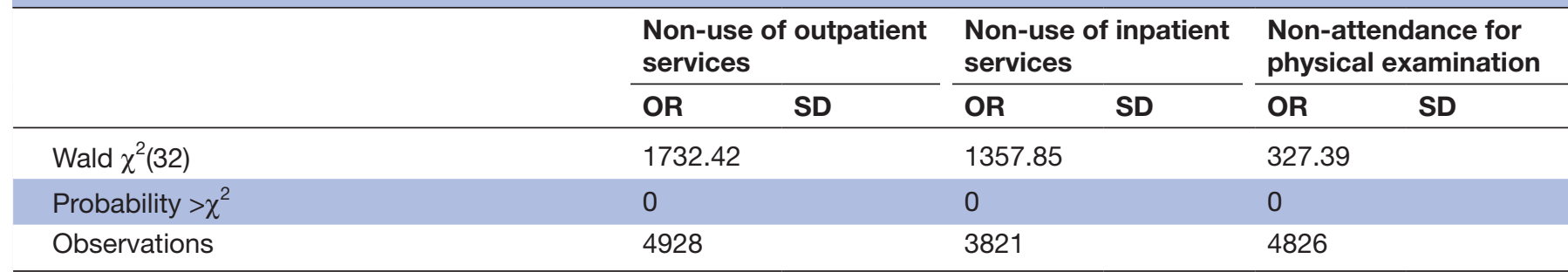

Estimates were weighted using individual sampling weights and adjusted for household and individual responses.

${ }^{*} \mathrm{P}<0.05$.

${ }^{\star *} \mathrm{P}<0.01$

${ }^{\star \star *} \mathrm{P}<0.001$.

ADL, activities of daily living; BMI, body mass index; NCMI, new cooperative medical insurance; UEMI, urban employee medical insurance; URMI, urban resident medical insurance.

Among enabling factors, we found a significant association between social health insurance and non-use of outpatient and inpatient services; hence, enrolment in social health insurance schemes may significantly reduce the likelihood of outpatient and inpatient foregone care among middle-aged and elderly people with chronic diseases. The highest income group ( $\geq ¥ 20533)$ demonstrated a significantly reduced likelihood of forgone inpatient and physical examination care compared with the lowest income group. Receipt of financial transfers increased the likelihood of non-use of outpatient services, and providing transfers was associated with reduced probability of foregone physical examination. Compared with middle-aged and elderly people living in urban areas, those in rural areas were significantly more likely to forego outpatient and physical examination care.

Among need factors, significant associations were detected between self-reported health, multiple chronic diseases, depression, and outpatient, inpatient, and physical examination foregone care. Middle-aged and elderly people with chronic diseases with fair, good or very good self-reported health had a lower likelihood of outpatient and inpatient foregone care compared with those with poor health status, and the likelihood decreased with increasing health status; however, individuals who self-reported their health as fair had a higher likelihood of foregone physical examination. Middle-aged and elderly people who had multiple chronic diseases demonstrated a higher probability of foregone outpatient and inpatient care, while exhibiting a lower likelihood of foregone physical examination. Individuals with depression had a higher likelihood of outpatient, inpatient and physical examination foregone care. Middleaged and elderly people with BMI values $>24$ had a lower probability of outpatient and inpatient foregone care. Any ADL increased the possibility of outpatient service foregone care. Drinking alcohol did not have a significant impact on any kind of foregone care, while smoking significantly increased the likelihood of foregone physical examination.

\section{DISCUSSION}

Along with the rapidly ageing population in China, the number of chronic diseases continues to rise and the elderly face serious health challenges. Although many studies have analysed healthcare utilisation in diverse population groups, few have examined foregone care in middle-aged and elderly chronically ill Chinese patients. This study, focusing on middle-aged and elderly people, was performed to analyse the prevalence of foregone healthcare and its associated factors in China.

In this study, we found that $10.21 \%$ and $6.84 \%$ of respondents had foregone outpatient and inpatient care, respectively; however, the prevalence of physical examination foregone care was relatively high $(57.88 \%)$. This may be attributable to the fact that Chinese social healthcare insurance schemes do not cover physical examinations; therefore, many middle-aged and elderly people are apt to forego physical examinations because of the associated economic burden. The prevalence of outpatient and inpatient foregone care rose, alongside increasing number of chronic diseases. Furthermore, the results of regression analysis (table 4) confirmed that respondents with multiple chronic diseases were more likely to forego outpatient and inpatient care. These data indicate that a greater demand for health services is associated with a higher probability of foregone outpatient and inpatient care. However, the likelihood of physical examination foregone care exhibited the opposite trend; people without chronic disease were most likely to forego physical examination and the prevalence decreased with increased number of chronic diseases. This result suggests that middle-aged and elderly individuals with chronic disease may have stronger awareness of preventative healthcare.

Among predisposing factors, our results indicate that the possibility of foregone outpatient and physical examination care decreases with increasing age. This is consistent with previous results literature reports. ${ }^{118}$ People in older age groups generally have more need for healthcare, related to more serious conditions, and may be more flexible with their time when seeking healthcare compared 
with younger individuals. Middle-aged and elderly people with chronic diseases who have fixed incomes (such as old age pensions) accessed more healthcare and exhibited a relatively low likelihood of foregoing care. This finding indicates that some medical financial assistance programmes may need to be extended, particularly with respect to unemployed and elderly retired people without pensions, to facilitate further reduction of the possibility of foregone care. In addition, our analyses revealed that middle-aged and elderly people with chronic diseases who were married and had large families exhibited a relatively high probability of foregone physical examination, consistent with a number of existing literature reports. ${ }^{19}$ We did not identify any association between sex and foregone care, which is also in line with several previous publications. ${ }^{12} 20$

Of enabling factors, our results demonstrate a strong association between socioeconomic variation and foregone care. Specifically, we found a significant association between household income level and foregone care; people with chronic diseases in the highest income group $(\geq ¥ 20533)$ reported less foregone inpatient and physical examination care compared with those in the lowest income group; however, we did not find a significant association between income level and outpatient foregone care, similar to previous studies. ${ }^{11} 1618$ These findings indicate that due to higher hospitalisation costs, income levels remain an important impact factor influencing the possibility of inpatient foregone care; however, for outpatient services, there were no significant differences in the likelihood of foregone care among different income groups, indicating that the universal coverage of medical insurance in China may be gradually improving the equity of outpatient care utilisation among middleaged and elderly people with chronic disease from different income levels. We also found that although social healthcare insurance can significantly reduce the level of outpatient and inpatient foregone care among chronically ill elderly patients, these schemes (except for urban employee medical insurance) may not significantly impact physical examination foregone care among elderly patients with chronic disease. Hence, policy efforts may need to focus on chronic elderly patients having urban resident medical insurance or new cooperative medical insurance, and strategies may need to be adjusted to promote the effective utilisation of preventive healthcare. Middle-aged and elderly people with chronic diseases who have received financial transfers from others exhibited a slightly higher likelihood of outpatient foregone care, while those who had made transfers to others had a significantly lower level of physical examination foregone care. Residents in rural areas had a significantly higher likelihood of outpatient and physical examination foregone care, as previously described. ${ }^{21}$ These findings may reflect the rural-urban income gap and differences in medical security in China.

As Andersen described, need factors best describe the true needs for healthcare. ${ }^{17}$ Consistent with previous studies, we found that middle-aged and elderly people with multiple chronic diseases or depression were more likely to forego outpatient and inpatient care. ${ }^{822} 23$ This may be because of high demands for medical services or lack of patient compliance among this group, likely leading to a relatively high probability of foregone care. Regarding physical examinations, multiple chronic diseases were associated with a reduced possibility of foregone care; however, depression was associated with an increased likelihood, consistent with published data. ${ }^{824-27}$ Self-reported health was negatively associated with outpatient and inpatient foregone care, except for individuals whose self-reported health was excellent. This indicates that the superior health of respondents was associated with a lower likelihood of foregone care ${ }^{28}$ ADL limitations did not affect inpatient and physical examination foregone care; however, these factors significantly increased the likelihood of outpatient foregone care. This finding maybe related to the fact that people with ADL often have some difficulty seeking outpatient treatment in a timely manner. ${ }^{29}$

The findings of this study may provide evidence on healthcare underutilisation and associated factors among middle-aged and elderly people. Some limitations of our study must be acknowledged. We evaluated foregone care only among middle-aged and elderly adults who perceived a need for healthcare but did not seek treatment; however, we did not take into account those who did not perceive the need for healthcare. Some patients objectively require healthcare, but do not perceive that need; therefore, the prevalence of foregone care may have been underestimated to some extent. In addition, cross-sectional data cannot be used to draw any causal conclusions about why these individuals may have foregone care.

\section{CONCLUSION}

Our findings reveal that the prevalence of foregone physical examination is relatively high among middle-aged and elderly people, and that this prevalence decreases with an increased number of chronic diseases. As a result of their greater demand for health services, respondents with chronic diseases demonstrated relatively higher likelihoods of both outpatient and inpatient foregone care. Hence, the adjustment of health insurance policies and improvements in the hierarchical medical system in China may be helpful to the effective utilisation of preventive care and outpatient and inpatient services. Some predisposing factors, including age, marital status, employment, education and family size; enabling factors, including social health insurance, income level and area of residence; and need factors, such as self-reported health, multiple chronic diseases and ADL, significantly affected foregone care among middle-aged and elderly people. Therefore, we may need to address these socioeconomic and demographic factors for reducing foregone care and enhancing the effective use of health services among 
middle-aged and elderly people in China. Finally, further work, including longitudinal studies, is required to gain a better understanding of the causal relationships between foregone care and its associated factors.

Acknowledgements The authors thank the National School of Development, Peking University and other members for their support and cooperation. The authors also thank Junlong Shen and Fang Pan who provided invaluable comments and suggestions for this paper.

Contributors XL was involved in data collection, analysis and writing the manuscript. ZW was involved in data analysis and took the lead in writing the manuscript. MC analysed the data and helped to write the final draft of the manuscript. LS supervised the study, contributed to the study design and wrote the manuscript. All the authors have read and approved the entire manuscript.

Funding This study was funded by the Education Department of Jiangsu Province (Grant number: 2014SJB175).

Disclaimer The funding body was not involved in the design of the study, data collection, analysis and interpretation, or in writing the manuscript.

Competing interests None declared.

Patient consent Obtained.

Ethics approval The study was approved by the ethics committee of Nanjing Medical University; reference number: 2017613.

Provenance and peer review Not commissioned; externally peer reviewed.

Data sharing statement Extra data can be accessed via the Dryad data repository at http://datadryad.org/ with the doi: 10.5061/dryad.n4b49kq

Open Access This is an Open Access article distributed in accordance with the Creative Commons Attribution Non Commercial (CC BY-NC 4.0) license, which permits others to distribute, remix, adapt, build upon this work non-commercially, and license their derivative works on different terms, provided the original work is properly cited and the use is non-commercial. See: http://creativecommons.org/ licenses/by-nc/4.0/

(C) Article author(s) (or their employer(s) unless otherwise stated in the text of the article) 2018. All rights reserved. No commercial use is permitted unless otherwise expressly granted.

\section{REFERENCES}

1. Alwan A. Global status report on non-communicable diseases 2010. Geneva, Switzerland: World Health Organization, 2011.

2. National Health and Family Planning Commission of the People's Republic of China. China report on Nutrition and noncommunicable chronic diseases 2015. China, Beijing: People health Press, 2015.

3. WHO. The world health report. Health systems financing: the path to universal coverage. Geneva: World Health Organization, 2010.

4. Yip WC, Hsiao WC, Chen W, et al. Early appraisal of China's huge and complex health-care reforms. Lancet 2012;379:833-42.

5. Luo J, Zhang X, Jin C, et al. Inequality of access to health care among the urban elderly in northwestern China. Health Policy 2009;93:111-7.

6. Niu T, Meng Q, Wang G, et al. Study on the health service utilization among elderly and its influencing factors in Shandong province. Chinese Primary Health Care 2010;24:7-8. In Chinese.

7. Zhang C, Lei X, Strauss J, et al. Health Insurance and Health Care among the Mid-Aged and Older Chinese: Evidence from the National Baseline Survey of CHARLS. Health Econ 2017;26:431-49.

8. Gong $\mathrm{CH}$, Kendig $\mathrm{H}, \mathrm{He}$ X. Factors predicting health services use among older people in China: An analysis of the China Health and Retirement Longitudinal Study 2013. BMC Health Serv Res 2016;16:63.
9. Albanese E, Liu Z, Acosta D, et al. Equity in the delivery of community healthcare to older people: findings from 10/66 Dementia Research Group cross-sectional surveys in Latin America, China, India and Nigeria. BMC Health Serv Res 2011;11:153.

10. Prince MJ, Wu F, Guo Y, et al. The burden of disease in older people and implications for health policy and practice. Lancet 2015;385:549-62.

11. Röttger J, Blümel M, Köppen J, et al. Forgone care among chronically ill patients in Germany-Results from a cross-sectional survey with 15,565 individuals. Health Policy 2016;120:170-8.

12. Zhou C, Ji C, Chu J, et al. Non-use of health care service among empty-nest elderly in Shandong, China: a cross-sectional study. BMC Health Serv Res 2015;15:294.

13. Åhs A, Burell G, Westerling R. Care or not care--that is the question: predictors of healthcare utilisation in relation to employment status. Int J Behav Med 2012;19:29-38.

14. Bodenmann $\mathrm{P}$, Favrat $\mathrm{B}$, Wolff $\mathrm{H}$, et al. Screening primary-care patients forgoing health care for economic reasons. PLoS One 2014;9:e94006.

15. Bryant T, Leaver C, Dunn J. Unmet healthcare need, gender, and health inequalities in Canada. Health Policy 2009;91:24-32.

16. Ronksley PE, Sanmartin C, Quan $\mathrm{H}$, et al. Association between chronic conditions and perceived unmet health care needs. Open Med 2012;6:e48-58.

17. Andersen R, Newman JF. Societal and Individual Determinants of Medical Care Utilization in the United States. Milbank Q 2005;83:Online-only.

18. Levesque JF, Pineault R, Hamel M, et al. Emerging organisational models of primary healthcare and unmet needs for care: insights from a population-based survey in Quebec province. BMC Fam Pract 2012;13:66

19. Mielck A, Kiess R, von dem Knesebeck O, et al. Association between forgone care and household income among the elderly in five Western European countries - analyses based on survey data from the SHARE-study. BMC Health Serv Res 2009;9:52.

20. Hopman P, Heins MJ, Korevaar JC, et al. Health care utilization of patients with multiple chronic diseases in the Netherlands: Differences and underlying factors. Eur J Intern Med 2016;35:44-50.

21. Yu H. Universal health insurance coverage for 1.3 billion people: What accounts for China's success? Health Policy 2015;119:1145-52

22. Peytremann-Bridevaux I, Chevrou-Severac H. Economic grand rounds: Financial burden of medical care and risk of forgoing care among Europeans with depressive symptoms. Psychiatr Serv 2008;59:840-2.

23. Himelhoch S, Weller WE, Wu AW, et al. Chronic medical illness, depression, and use of acute medical services among Medicare beneficiaries. Med Care 2004;42:512-21.

24. Srivastava D, McGuire A. Patient access to health care and medicines across low-income countries. Soc Sci Med 2015; $133: 21-7$

25. Hansen AH, Halvorsen PA, Ringberg U, et al. Socio-economic inequalities in health care utilisation in Norway: a population based cross-sectional survey. BMC Health Serv Res 2012;12:336.

26. Verhagen I, Steunenberg B, de Wit NJ, et al. Community health worker interventions to improve access to health care services for older adults from ethnic minorities: a systematic review. BMC Health Serv Res 2014;14:497.

27. Gotsadze G, Murphy A, Shengelia N, et al. Healthcare utilization and expenditures for chronic and acute conditions in Georgia: does benefit package design matter? BMC Health Serv Res 2015;15:88

28. Bähler C, Huber CA, Brüngger B, Caroline B, Carola AH, Beat B, et al. Multimorbidity, health care utilization and costs in an elderly community-dwelling population: a claims data based observational study. BMC Health Serv Res 2015;15:23.

29. Jang SN, Rhee S, Cho SI. Functional Limitation and Medical Care Utilization among the Community- dwelling Elderly. J Korean Geriatr Soc 2007; 11:198-204.

30. Wallace RB, Herzog AR. Overview of the Health Measures in the Health and Retirement Study. J Hum Resour 1995;30:S84-S157. 